\title{
The effect of soft drink on proliferation, cell cycle analysis, and integrin expression of human foreskin fibroblast
}

\begin{abstract}
Cola is a globally distributed and consumed beverage. Soft drinks may contribute significantly to human health conditions and diseases associated with the Western Diet, consisting mainly of a high-volume intake of processed sugars, red meats and high fat foods. Ingredients comprising this beverage are undefined and may have an impact on the behavior of normal human cells, including the controlled cell proliferation, cell cycle and innate expression of $\alpha 5 \beta 1$ integrin expression of human foreskin fibroblasts (HFF-1). The proliferation of HFF-1 was examined in the presence of an array of concentrations of Cola supplementation $(0.5 \%, 1.0 \%, 1.5 \%, 2.0 \% 6.0 \%, 8.0 \%$, and $10.0 \%)$ in conditions defined by the initial presence of $10 \mu \mathrm{g} / \mathrm{mL}$ fibronectin. In the presence of increasing concentrations of Cola a decrease in the proliferation of HFF-1 cells is observed. Additionally, there are an increased proportion of HFF-1 cells in the $\mathrm{G}_{1}$ phase in an environment consisting of increasing concentrations of Cola. There was no observed increase or decrease in the $\alpha 5$ or $\beta 1$ integrin expression. With these findings, we suggest that more research should be conducting to better understand the effects resulting from Cola in larger concentrations.
\end{abstract}

Volume 5 Issue 4 - 2018

\author{
Eckhart Kyle,' Vaghasia Nikita,' Kniseley \\ Atherton,' Bucci, Brianna,' Bill Tawil',' \\ 'Department of Biotechnology \& Bioinformatics, California \\ State University, USA \\ ${ }^{2}$ Department of Bioengineering, UCLA School of Engineering, \\ USA
}

Correspondence: Bill Tawil, Department of Bioengineering, UCLA School of Engineering, 420 Westwood Plaza, Room 5121, Engineering V. P.O. Box: 951600, Los Angeles, CA 90095-1600, USA, Fax (310) 794-5956, Email bill.tawil@csuci.edu

Received: April 08, 2018| Published: July 20, 2018

Keywords: collagen, fibronectin, proliferation, morphology, RGD, integrins, cell behavior

Abbreviations: HFF, human foreskin fibroblasts; ECM, extracellular matrix; DMEM, Dulbecco's modified eagle's medium; FBS, fetal bovine serum; PBS, phosphate buffer saline; FACS, fluorescent activated cell sorting

\section{Introduction}

Sweetened beverage intake by Americans has increased 135\% from 1977 to $2001 .^{1}$ Cola soft drinks are predominantly composed of varying chemicals which function as preservatives, colorings, and artificial flavoring. ${ }^{2}$ However, due to trade secrets, there are unidentified ingredients included, such as 'merchandise $7 \mathrm{x}$ '. Increased consumption of fructose concentrated beverages is a key component in the classification of the Western Diet, characterized by high intake of saturated and omega- 6 fatty acids, reduced omega- 3 fat intake, an overuse of salt, and processed sugars., ${ }^{3,4}$ The overconsumption of these beverages may have links to the risk in numerous human health disorders including obesity, dental/bone disorders, diabetes mellitus, and cardiovascular disease. ${ }^{5}$ Ingredients comprising these beverages may have an impact on the behavior of key cell types critical in wound healing. ${ }^{6-12}$

Fibroblasts are spindle-shaped, anchorage dependent, members of the connective-tissue family. Fibroblasts secrete type I and III collagen into the extracellular matrix (ECM) to help isolate and repair damaged tissue. ${ }^{13}$ Fibroblasts bind directly to fibronectin fibrils which subsequently attach to collagen scaffolds which provide structure, support, growth and communication. ${ }^{14}$ The ECM is made of growth factors and proteins that directly affect the differentiation, proliferation, and migration of cells. ${ }^{15}$ Fibronectin is a ubiquitous ECM glycoprotein, joined by disulfide bonds, that are assembled into a fibrillar matrix. Fibronectin promotes the recruitment of platelets, neutrophils, monocytes, fibroblasts, and endothelial cells to wounds. ${ }^{16}$ Integrins tether fibronectin dimers initiating fibronectin-fibronectin interactions creating an insoluble fibrillar ECM that aids proliferation, adhesion, and migration of cells during the wound healing process. ${ }^{16-18}$

\section{Hypothesis}

Due to the ingredients comprising of cola beverages, these intricate mechanisms may become manipulated, allowing for human health issues involved with cell proliferation and migration..$^{7-9}$ Imbalance within these processes may result in the delay of tissue regeneration process. Soda cola concentrations, $0.5,1.0,1.5,2.0,4.0,6.0,8.0$, and $10 \%$ were used on Human Foreskin Fibroblasts, a combined cell line derived from two non-cancerous human foreskin samples in the presence of varying extracellular matrix (ECM), fibronectin, ${ }^{19}$ to observe any changes from these conditions. Indications from ingredients in this study suggest that increased $\beta 1$ expression may yield a greater increase in $\mathrm{G}_{1}$ phase decreasing cellular proliferation with the increase in cola concentration.

\section{Materials and methods}

\section{HFF-I cell culture and preparation}

Human foreskin fibroblasts (HFF-1) from ATCC (Manassas, VA, USA) were cultured in Dulbecco's Modified Eagle's Medium (DMEM) (Hyclone Ge Healthcare Life Sciences, Waltham, MA USA), $15 \%$ fetal bovine serum (FBS), $1 \%$ penicillin/streptomycin, and $1 \%$ glutamax from Thermo Fisher Scientific (Waltham, MA USA) in a T75 flask, Thermo Fisher Scientific (Waltham, MA USA). Plastic bottled Coca-Cola ${ }^{\mathrm{TM}}$ (Coca-Cola ${ }^{\mathrm{TM}}$, Atlanta, GA) was obtained on campus at California State Channel Islands University, from the vending machine near the laboratory in Sierra Hall. Cola was sterilized and decarbonized before dilution in HFF-1 Media at $0.5 \%, 1 \%, 1.5 \%, 2 \%, 4 \%, 6 \%, 8 \%$ and $10 \%$. Cola $\mathrm{pH}$ was initially observed at 7.4 in a 1:1 ratio with HFF-1 media. Cola was vacuum filtered using Stericup Sterile Vacuum Filters (EMD Millipore, Temecula, CA). Cells were maintained in an incubator at $37^{\circ} \mathrm{C}$ and $5 \% \mathrm{CO}_{2}$. HFF-1 cells were observed with a phase contrast microscope CKX41 from Olympus (Waltham, MA USA) for confluency. HFF-1 cells were washed with sterile phosphate buffer saline (PBS) Hyclone 
GE Healthcare Life Sciences (Waltham, MA USA). HFF-1 cells were trypsinized using $0.25 \%$ Trypsin-EDTA from Genclone (San Diego, CA, USA). Cells were observed under the phase contrast microscope during 10minute incubation. HFF-1 cells were neutralized with HFF1 media. Mixture was transferred and centrifuged at 3000rpms in an Eppendorf centrifuge 5804R-15 AMP version (Hamburg, Germany). Supernatant was poured and suspended in HFF-1 media. An Auto Cellometer T4 (Nexcelom, Lawerence, MA) was used for all cell count calculations. Calcein-AM (Catalog \#C3099, ThermoFisher, Waltham, MA) was used for staining, imaging and analyzation via Multimode Analysis Program, (Molecular Devices, Sunnyvale, CA). Fluorescent images were taken using Olympus IX71 inverted Fluorescent microscope from Olympus (Waltham, MA, USA) using a Cy3 filter at 10x magnification. All graphs and calculations were completed using Microsoft Excel. The statistical comparison between media and concentrations used was made by paired t-test (two-sample assuming unequal variances); $\mathrm{P}<0.05$ was considered significant.

\section{D-cell proliferation assay}

Cola was supplemented in HFF-1 media in the following concentrations: $0.5 \%, 1 \%, 1.5 \%, 2 \%, 4 \%, 6 \%, 8 \%$ and $10 \%$ from Coca-Cola $^{\mathrm{TM}}$ (Los Angeles, CA, USA) and HFF-1 media. Cells were plated onto a 24 -well plate, initially coated with $10 \mu \mathrm{g} / \mathrm{ml}$ fibronectin at a density of 10,000 cells/ well and incubated at $37{ }^{\circ} \mathrm{C}, 5 \% \mathrm{CO}_{2}$. After 1hour, 3 days and 7 days of incubation wells were washed thrice, with PBS and incubated in the dark with calcein-AM. Fluorescent samples were quantified using FilterMax F5 Multi-Mode microplate reader from Molecular Devices.

\section{Cell cycle analysis}

HFF-1 cells were seeded at a density of 10,000 cells/well in duplicates at $1.5 \%, 6 \%$ and $10 \%$ Cola supplemented conditions on 24 well plates initially coated with $10 \mu \mathrm{g} / \mathrm{ml}$ fibronectin. HFF-1 with no initially coated fibronectin was also performed. Cells were harvested into $1.5 \mathrm{~mL}$ Eppendorf tubes, centrifuged at $15,000 \mathrm{rpm}$, and suspended into $1 \mathrm{~mL}$ of PBS followed by another centrifugation at 5000rpm. After resuspension with $300 \mu \mathrm{L}$ PBS, $700 \mu \mathrm{L} 100 \%-20^{\circ} \mathrm{C}$ high grade ethanol was added. Cells were stored at $-20^{\circ} \mathrm{C}$ until analysis. Cells were centrifuged at $200 \mathrm{~g}$ for 5 minutes and suspended with $200 \mu \mathrm{L}$ Guava Cell Cycle Reagent (Propidium Iodide solution), followed by a 30minute dark room incubation. Samples were analyzed using Guava EasyCyte flow cytometer from EMD Millipore (Hayward, CA, USA). Cell cycle analysis was analyzed at 5000 events per reading.

\section{Integrin expression}

HFF-1 cells were seeded onto a 24 well plate coated with $10 \mu \mathrm{g}$ $\mathrm{ml}$ fibronectin at a density of 10,000 cells/well in $1.5 \%, 6 \%$, and $10 \%$ Cola supplemented media. Plates were incubated for 7 days. Post incubation, cells were washed with PBS, trypsinized, centrifuged and suspended in $1 \mathrm{ml}$ cold PBS using ice buckets. Cells were washed again with PBS and centrifuged at 15,000rpm for 5minutes. Cells were suspended in $800 \mu \mathrm{l}$ cold PBS. A $100 \mu \mathrm{l}$ was aliquoted per each media condition of 25,000 cells. $2.5 \mu \mathrm{l}$ of either $\alpha 5$ (Mouse AntiHuman CD49E Conjugate Monoclonal (Alpha 5 Antibody) EMD Millipore) or $\beta 1$ (FITC Mouse Anti-Human CD29 (Beta 1 Antibody) Quantobio, Newbury Park, CA) antibodies were added and incubated on ice in the dark for 1hour. Two cold PBS and centrifugation wash steps were completed after incubation. Samples were analyzed using Millipore Guava easyCyte (EMD Millipore, Billerica, MA).

\section{Results}

\section{Initial adhesion}

We first examined the initial adhesion, the rate at which cells first attach to the plate, on 24 well plates initially coated with fibronectin in the presence of Cola. Cells were seeded at 10,000cells per well in $0.5 \mathrm{~mL}$ of regular media or Cola concentration media and observed after a 1hour incubation period. HFF-1 cells showed activation as the monolayer shown in $\operatorname{Day}_{0}(\mathrm{~s})$ (kept at relatively low density) and over time, losing their distinguishing round shape, and flatten down on the substratum leading to adhesion and cell proliferation.

$\mathrm{N}=9$. Cola was stored at an average temperature based on human consumption (refrigerator) and then heated in a bath at $37^{\circ} \mathrm{C}$ before plating. Regular Media was hovering just above $\sim 150 \%$. $0.5 \%$ Cola decreased to $\sim 125 \%$. $1.0 \%$ had a slight increase to $\sim 128 \%$ proliferation. The lowest percentage proliferation was observed at $1.5 \%$ Cola concentration at $100 \%$. 2.0\% Cola increased to $\sim 160 \%$. $4.0 \%$ Cola decreased slightly to $\sim 150 \%$ proliferation. $6 \%$ Cola decreased to $\sim 130 \%$. $8 \%$ Cola shows the highest initial adhesion percentage at $\sim 220 \%$. $10 \%$ Cola decreased to $\sim 150 \%$.

We have compared the initial adhesion at day 0 (1 hour incubation). The data compares all media types to the lowest initial adhesion percentage which was observed at $1.5 \%$ Cola concentration at Day 0 (1hour incubation). $1.5 \%$ Cola initial adhesion was set to $100 \%$ percent for comparison between media conditions. The two lowest initial adhesion percentages were observed at $1.5 \%$ and $6 \%$ Cola conditions. The highest initial adhesion observed was at $8 \%$ Cola concentration. All P-values marked with '*' were considered statistically significant $(\mathrm{P}<0.05)$ when compared to HFF-1 cells cultured in regular HFF1 media. Large overlapping standard deviations make data not statistically significant.

In conclusion, there is no observed trend from initial adhesion with the effect of Cola. Initial adhesion is the rate at which cells first attach to the plate.

\section{Cellular proliferation}

Figure 1 examines HFF-1 proliferation on 24 well plates initially coated with fibronectin in the presence of Cola. Cells were seeded at 10,000 cells per well in $0.5 \mathrm{~mL}$ of regular media or Cola concentration media and observed at Day 0, Day 3, and Day7. Cell proliferation results are a measure of HFF-1 proliferation on Day 0, Day 3, and Day 7 and a comparison of Day 3 and Day 7 proliferations to Day 0 readings of the same media conditions. Proliferation comparisons between media conditions are able to be made because of percentage representation of proliferation.

Our data shows that HFF-1 cell proliferation across the Cola concentrations decrease after $1.5 \%$ Cola at day 3 and day 7. Day 3 regular media increased to $\sim 340 \%$. Day 7 regular media increased to $\sim 570 \% .0 .5 \%$ Cola concentration had the highest cellular proliferation observed. Day $30.5 \%$ Cola increased to $\sim 565 \%$. Day $70.5 \%$ increased to $\sim 620 \%$. Cola concentrations; $1.0,1.5,2.0,4.0,6.0,8.0$, and $10 \%$ show a decreasing trend in cell proliferations. Day $31.0 \%$ Cola increased to $\sim 290 \%$, a $50 \%$ decrease from regular media. Day $71.0 \%$ increased to $\sim 600 \%$. Day $31.5 \%$ Cola increased to $\sim 310 \%$, a $30 \%$ decrease from regular media. Day $71.5 \%$ increased to $\sim 610 \%$.

Day $32.0 \%$ increased to $290 \%$. Day $72.0 \%$ increased to $400 \%$. Day $34.0 \%$ increased to $280 \%$. Day $74.0 \%$ increased to $400 \%$. Day 
$36.0 \%$ increased to $\sim 290 \%$. Day $76.0 \%$ increased to $\sim 450 \%$. Day 3 $8.0 \%$ increased to $\sim 190 \%$. Day $78.0 \%$ increased to $\sim 270 \%$. Day 3 $10 \%$ increased to $\sim 120 \%$. Day $710 \%$ increased to $\sim 200 \%$.

We have compared results from Day 0 (1hour incubation), to Day 3, and Day 7. Day 0 proliferation percentages are presented as $100 \%$. Our data shows that HFF-1 cell proliferation across the Cola concentrations decrease after $1.5 \%$ Cola at Day 3 and Day 7 . There is a trend for an increase in the proliferation of HFF-1 in the presence of low concentrations $(0.5 \%, 1.0 \%$, and $1.5 \%)$ of Cola and decrease in proliferation in the presence of higher concentrations $(2.0 \%, 4.0 \%$, $6.0 \%, 8.0 \%$, and $10.0 \%$ ) of Cola on Day 7. Day 3 proliferation shows a peak at $0.5 \%$ Cola and a negative correlation between proliferation and Cola concentration. The greatest rate of proliferation was seen in $0.5 \%$ Cola from Day 0 to Day 3. The lowest rate of proliferation was seen in $0.5 \%$ Cola from Day 3 to Day 7 . In conclusion, our results show a negative correlation between increasing concentration of Cola and HFF-1 proliferation. Cell proliferation results in an increase HFF1 cell growth, and defined by the balance between cell divisions and cell loss through cell death or differentiation.

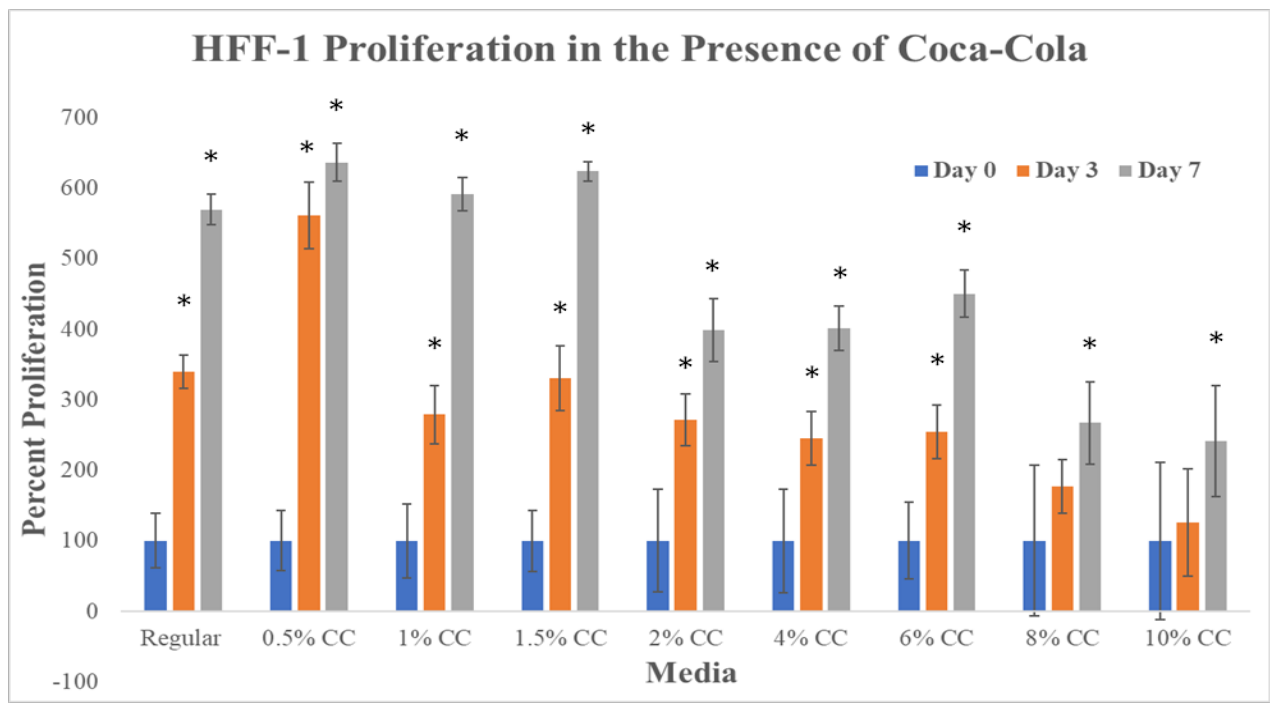

Figure I Cell Proliferation.

There is a decreasing trend observed with increase in the concentration of Cola in cell proliferation. Graph of HFF-I cell proliferation on I0 $\mu$ g/ $\mathrm{mL}$ fibronectin initially coated wells. Black brackets indicate standard deviation. $\mathrm{N}$ of 9.All $\mathrm{P}$ values marked with '*' were $\mathrm{P}<0.05$, considered statistically significant when compared to Regular Media. Day 3 proliferation shows a peak at $0.5 \%$ Cola and a negative correlation between proliferation and Cola concentration. The greatest rate of proliferation was seen in $0.5 \%$ Cola from Day 0 to Day 3. The lowest rate of proliferation was seen in $0.5 \%$ Cola from Day 3 to Day 7. Cells were seeded at 10,000 cells per well in $0.5 \mathrm{~mL}$ of regular media or Cola concentration media. These cultures were incubated for I hour, 3 days, and 7 days, after which, were analyzed for their rate of proliferation by using a prepared calcein-AM suspension and the FilterMax F5 microplate reader.

\section{Cell morphology}

Figure 2 shows calcein-AM staining of HFF-1 cell morphology at Day 0,3 , and 7. Calcein-AM is excited between the wavelengths of $495-515 \mathrm{~nm}$. It is transported (diffused) through the cellular membrane, passively, as a colorless reagent into live cells. While calcein-AM is a useful tool for visualizing cell morphology, extended incubation time of HFF-1 cells in calcein-AM is toxic. Cells were seeded at 10,000 cells per well in $0.5 \mathrm{~mL}$ of regular media or Cola concentration media and observed at Day 0, Day 3, and Day7. After entering the cell, intracellular esterase (hydrolase enzyme that splits esters into an acid and alcohol through hydrolysis) will remove the actomethoxy group, trapping inside the cell, emitting fluorescence through the cytoplasm with a low background. The dead cells do not carry the esterase.

Day 0 HFF-1 cells appear round and share similar size to one another. Day 0 images show similar cell concentration within the wells indicating that initial adhesion of HFF-1 cells was similar in all media conditions. Day 3 and $70.5 \%$ Cola photos show high amounts of cell density which reflects cell proliferation results from Figure 1. There is a trend from the images that the increasing Cola concentration decreases HFF-1 confluency at Day 3 and Day 7. The spindle-like appearance can be seen at Day 3 and Day 7. In conclusion, the Fluorescent images in Figure 2 confirm cell proliferation was highest in lower Cola concentrations compared to higher.

\section{Cell cycle analysis}

Figure 3 examines the cell cycle of HFF-1 in the presence of Cola concentration on initially coated fibronectin at Day 7. The analysis of these phases is based on the stoichiometric manner where the amount of PI stain (Propidium Iodide) is directly proportional to the amount of DNA within the cell. PI is an intercalating dye which binds to the DNA and double stranded RNA. Stained diploid cells that are analyzed via flow cytometry will show narrow readings of a distribution of fluorescent intensities. Figure 3 shows a quantitative histogram of the averages calculated for percent positive of HFF-1 phases.

There is a trend for lower $\mathrm{G}_{1}$-phase presence at low concentrations $(0.5 \%$ and $1.0 \%)$ of Cola when compared to Regular media in $10 \mu \mathrm{g} /$ $\mathrm{mL}$ fibronectin initially coated wells. There is a trend for higher $\mathrm{G}_{1}-$ phase presence at high concentrations $(4.0 \%, 6.0 \%, 8.0 \%$, and $10.0 \%)$ of Cola when compared to Regular media in $10 \mu \mathrm{g} / \mathrm{mL}$ fibronectin initially coated wells. There is a trend for decreased S-phase presence as Cola concentrations increase when compared to Regular media in 
$10 \mu \mathrm{g} / \mathrm{mL}$ fibronectin initially coated wells. G2/M phase data points had notable wide standard variations with no trend observed from the data in the presence of Cola.
In conclusion, $\mathrm{G}_{1}$ phase increases as Cola concentration increases. A trend can be observed of the S phase decreasing from $13 \%$ at Cola $0.5 \%$ to $<10 \%$ at $10 \%$ Cola. $\mathrm{G} 2 / \mathrm{M}$ phase data points had notable wide standard variations with no trend observed from the data.
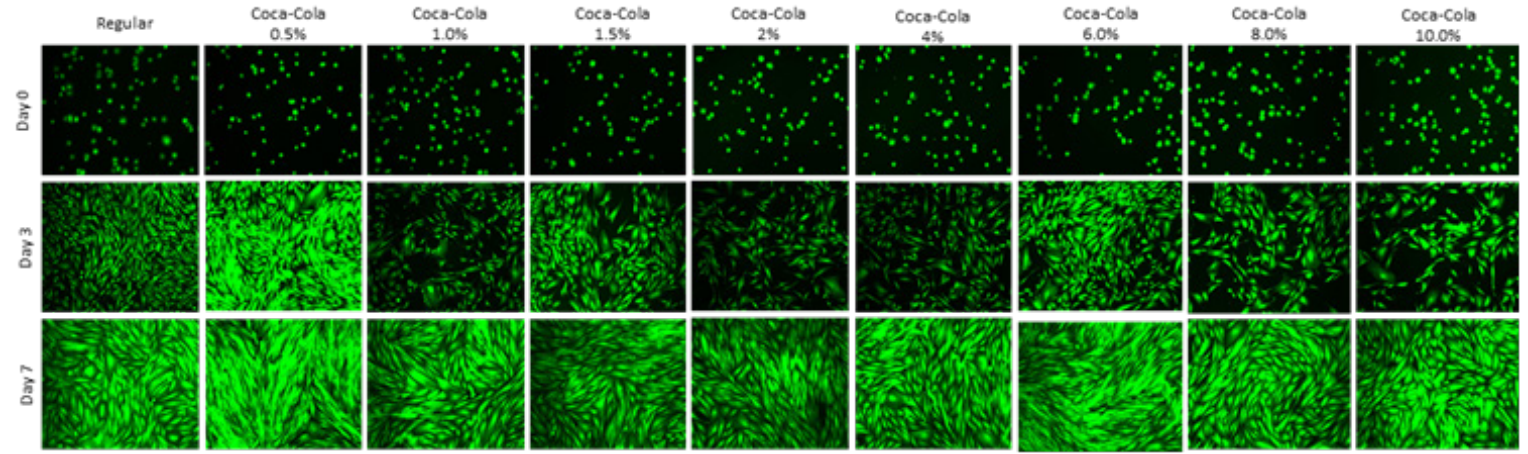

Figure 2 Cell Morphology.

Morphological analysis does not correlate with the HFF-I Proliferation on day 3 but it correlates on day 7. Highest HFF-I cell proliferation was observed on Cola $0.5 \%$ on Day 3 and Day 7. The calcein-AM staining of HFF-I cells show the morphology from round appearance Day 0 to the spindle-like appearance by Day 3 and 7 . The wells were initially coated with fibronectin I $0 \mathrm{\mu g} / \mathrm{mL}$. HFF-I media, $0.5 \%$, and I.0\% look subjectively similar (based on appearance). $8 \%$ and $10 \%$ concentrations had notable large gaps between cell clusters in wells. Photos at $8 \%$, and $10 \%$ appear more dimly lit and confirm cell proliferation decrease in Figure 2. Calcein-AM is excited between the wavelengths of $495-515 \mathrm{~nm}$. It is transported (diffused) through the cellular membrane, passively, as a colourless reagent into live cells. After entering the cell, intracellular esterase (hydrolase enzyme that splits esters into an acid and alcohol through hydrolysis) will remove the actomethoxy group, trapping inside the cell, emitting fluorescence through the cytoplasm with a low background. The dead cells do not carry the esterase.

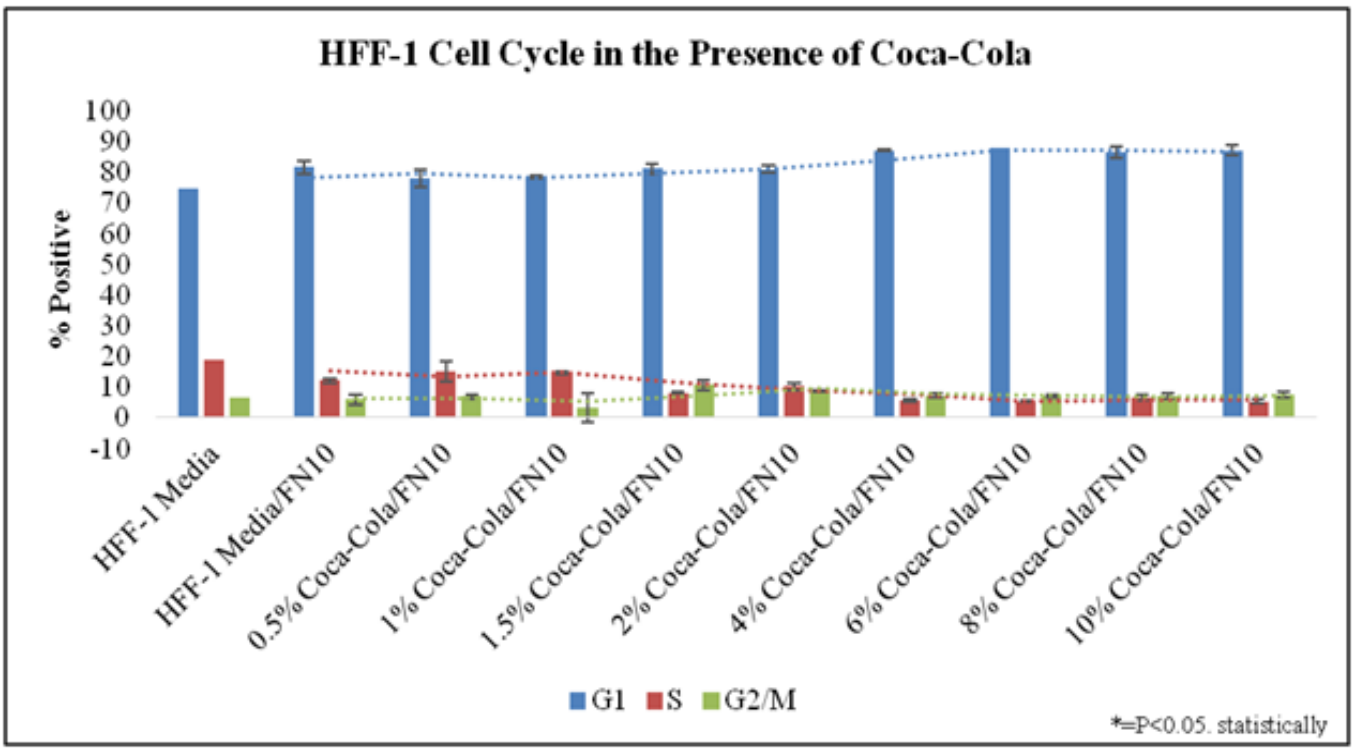

Figure 3 Cell Cycle Analysis.

There is an increase of $\mathbf{G I}$ and decrease in G2/M Phase of Cell cycle analysis as Cola concentration increases. $N=2$. HFF- I cells were harvested, washed, and fixed, then on the day of use, were suspended in PI solution which binds easily in between the bases of the DNA with no preference. ${ }^{31}$ The percentage of cells in GI phase, S phase and G2/M phase were detected using the Millipore Guava easyCyte flow cytometer. The cell cycle was analyzed in the presence of low and high concentrations of Cola. It is suggested by Figure I that in increased concentrations of Cola, there is an increase in the percentage of cells in the GI phase, while there is also a decrease in the percentage of cell in the S phase. Day 3:GI phase decreased between regular versus regular + fibronectin. $S$ phase increased by $8 \%$ without fibronectin. The $\mathrm{S}$ phases of all conditions show no noticeable trend at Day 3. There is a slight decrease in G2/M phase as Cola concentration increases. S phase decreasing from $13 \%$ at Cola $1.5 \%$ to $<10 \%$ at $6 \%$ Cola and $<10 \%$ at Cola $10 \%$. G2/M phase data points had no notable trends observed from the data. Day 7: GI phase decreased between regular versus regular + fibronectin. S phase increased by $8 \%$ to $20 \%$ in HFF-I cells coated without fibronectin. The $\mathrm{S}$ phases of all conditions showed no noticeable trend at Day 7. The $\mathrm{S}$ phases of all conditions showed no noticeable trend at Day 7. G2/M phase data points had notable trends observed.

Citation: Kyle E, Nikita V,Atherton K, et al.The effect of soft drink on proliferation, cell cycle analysis, and integrin expression of human foreskin fibroblast.J Appl Biotechnol Bioeng. 2018;5(4):212-220. DOI: 10.15406/jabb.2018.05.00140 


\section{FACS analysis}

The antibodies used in FACS analysis for integrin expression binds to the minor grooves of the DNA helix and does not bind to RNA. Antibodies consist of a variable region (Fab portion) that will bind to the epitope (fibronectin or collagen) and the constant region when specified. ${ }^{20}$

Fluorescent Activated Cell Sorting (FACS) results using Guava Incyte software of HFF-1 cells after 7 day of incubation in the presence of $1.5 \%, 6 \%$, and $10 \%$ Cola and HFF-1 growth media on wells initially coated with $10 \mu \mathrm{g} / \mathrm{mL}$ fibronectin. The vertical black line depicted in Figure $4 \mathrm{~A}-4 \mathrm{H}$ was used to determine shifts in integrin expression. Figure 4A \& 4B establishes baseline for integrin expression activity.

Figures $4 \mathrm{C}-4 \mathrm{H}$ shows no change in the expression of $\alpha 5$ or $\beta 1$ integrin. Black peaks indicate no antibodies added. High background was noted. Black peaks indicate no antibodies added. High background was noted. In conclusion, no change in $\alpha 5$ or $\beta 1$ integrin expression by HFF-1 cells in the presence of Cola was observed.

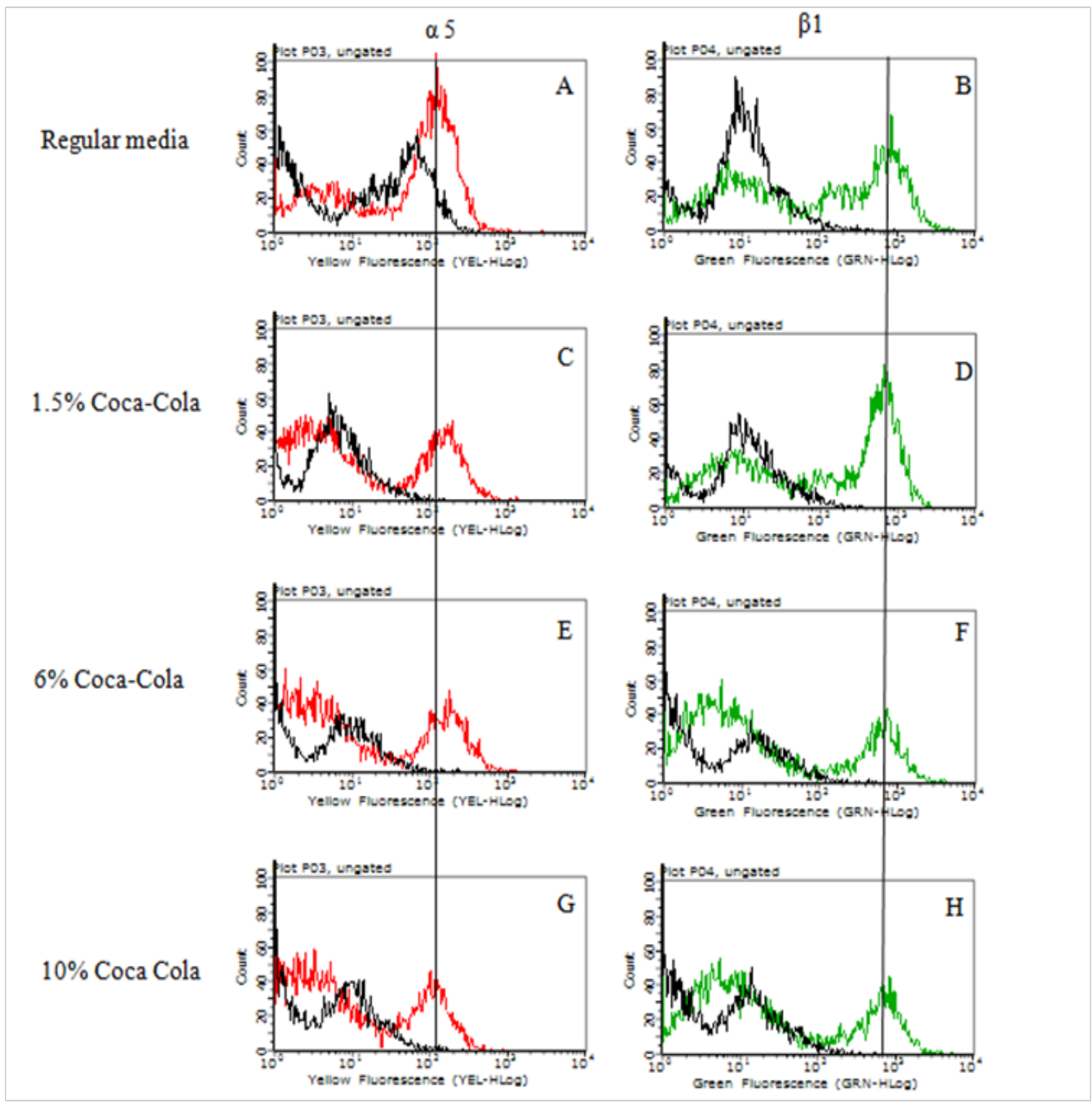

Figure 4 Integrin Expression.

Increase in expression of $\alpha 5 \beta$ I integrin in Regular, 1.5\%,6\%, and 10\% Cola. Fluorescent Activated Cell Sorting (FACS) results using Guava Incyte software of HFF-I cells after 7-day of incubation in the presence of I.5\% Cola, $6 \%$ Cola and HFF-I growth media on wells initially coated with $10 \mu \mathrm{gg} / \mathrm{mL}$ fibronectin. The black line depicted in Figure $4 \mathrm{~A}-4 \mathrm{H}$ was used to determine shifts in integrin expression. Figure $2 \mathrm{~A} \& 2 \mathrm{~B}$ establishes baseline for integrin expression activity. There is no observed trend in $\alpha 5$ or $\beta$ I expression with any conditions compared to regular. Black peaks indicate no antibodies added. High background was noted. $\mathrm{N}=2$

\section{Discussion}

Soft drinks have been a target for their high sugar content and otherwise unknown ingredients, in their contribution to risk factors in human diseases. ${ }^{6}$ Fibroblasts rely on an intricate balance of cellular mechanisms such as proliferation, focal adhesion, migration, and apoptosis for survival. To maintain proper functioning of a tissue, cells must be able to communicate efficiently to neighboring and far reaching cells. ${ }^{15}$ Human foreskin fibroblasts migrate and attach themselves to ECM proteins by focal adhesion to fibronectin. This is done through integrin binding $\alpha 5 \beta 1$ to the RGD (Arg-Gly-Asp) cell-binding domain. ${ }^{21,22}$ As conformational change occurs, integrin clustering and exposed fibronectin binds to the sites promoting fibronectin-fibronectin interaction, critical for initial adhesion and wound healing. ${ }^{23}$ During wound repair, this allows for the arrangement for new granular tissue, producing and renewing the extracellular matrix. $^{24,25}$ 


\section{Initial adhesion}

An inverse relationship between HFF-1 initial adhesion and HFF1 proliferation was expected. An increased attachment rate to the surface would indicate a stronger adherence and a lesser detachability from the HFF-1 cells. ${ }^{26}$ Therefore, an increase in initial adhesion would yield a lesser proliferation however; no statistical difference in initial adhesion was observed when HFF-1 cells were incubated for 1 hour in the presence of Cola and regular media. There is a trend that low concentrations of Cola have lower initial adhesion than higher concentrations of Cola.

The ability of fibronectin to induce organization of important proteins to promote adhesion-dependent cell-growth could be the reason behind fibroblast proliferation in regular media. ${ }^{27-30}$ There was more cell proliferation of fibroblasts in the presence of high levels of Cola, such as $0.5 \%$ Cola Increased acidity may have inactivated fibroblast growth factor but the $\mathrm{pH}$ of the media remained normal even in 1:1 ratio of Cola to HFF-1 media. ${ }^{31}$ High fructose corn syrup is about $55 \%$ fructose and can have adverse effects on cells due to high concentration of a minor sugar. ${ }^{32,33}$

Fibroblasts migrate on 2-dimensional surfaces using actin-rich extensions at the ends also known as lamellipodia. Under the plasma membrane, the actin filaments are polarized. This enables the exertive force causing opposing tension, pushing back into itself and through integrin mediated adhesion paired with cytoskeleton to a substrate, allows these forces to contract. ${ }^{34-37}$ Therefore, increased adhesion could cause a delayed detachment and retraction of the lagging portion of the cell. In contrast, both collagen and fibronectin increase migration of fibroblast cells. ${ }^{28,38-40}$ Having both fibronectin and Cola together show that the possible increased initial adhesion effect of high concentrations of Cola is greater than the decreased initial adhesion effect that fibronectin has on HFF-1 cells.

\section{Cell proliferation}

Calcein-AM stains were used over other assays such as MTT due to the cellular retention. ${ }^{41}$ While MTT are robust assays, ascorbic acid, found in soft drinks can alter these results. Due to the unknown knowledge of Cola on cellular proliferation, if there was over confluence paired with an MTT assay, inability to record accurate readings. ${ }^{42,43}$ A significant decrease in HFF-1 proliferation incubated in the presence of increasing amounts of Cola is demonstrated in Figure 1. This suggests that because there is an increase in the initial adhesion, therefore it requires more energy for these cells to detach, go through DNA duplication, and cell division. Phosphoric acid could be blocking necessary divalent cations such as $\mathrm{Mg}^{2+}$, $\mathrm{Mn}^{2+}$, and $\mathrm{Ca}^{2+}$ used in integrin receptors for binding ligands. ${ }^{44} \mathrm{Cola}$ at lower concentrations of $0.5 \%$ showed higher cell proliferation and lower cellular adhesion. It has been found that carbonated soft drink consumption is associated with shortening of telomere length critical in cell viability and chromosomal stability. ${ }^{45}$ There are multiple ingredients within Cola that affects cells. Increased caffeine levels reduce collagen expression in the liver and therefore reduce levels of TGF $\beta$ reducing fibrosis in epithelial cells. ${ }^{46}$ Fibroblasts incubated in various caffeine concentration express $\beta 1$-integrins and insulin growth like receptors which contribute to the inhibition of collagen biosynthesis..$^{33}$-methylimidazole was a coloring agent that since has been removed due to its effect on cellular proliferation, including DNA breaking and DNA fragmentation. ${ }^{47,20}$ Sugar substitutes influence angiogenesis, inducing regenerative cytokine production, activating
MAPKs, enhancing IL-6 and VEGF. This result in angiogenesis, an important factor in wound healing and tumors. ${ }^{48}$

\section{Cell cycle analysis}

Cell Cycle analysis showed that higher number of cell arrest in $G_{1}$ phase and lower in $S$ and $G_{2} / M$ phase. $G_{1}$ phase arrest occurs when there is an increase in the number of cells that are expanding in size but are prevented from duplicating their chromosomes. ${ }^{49} \mathrm{~A}$ rapid accumulation of G1 phase cells before S phase progression may be a strategy for safety in cell proliferation due to a signal from vascular injury. ${ }^{50}$ Fibroblasts arrested at the G1-S transition lack regulator kinases observed in human cancers. ${ }^{51}$ Other studies have shown that $\mathrm{S}$ phase fibroblasts arrest at $\mathrm{G}_{0}-\mathrm{G}_{1}$ phase by interaction with collagen type I. ${ }^{52} \mathrm{~S}$ phase appeared to be decreasing as Cola concentration increased. The transition from proliferation to senescence is driven by the endogenous and exogenous stress factors of increased concentration. Senescent cells remain metabolically operative but exit the cell cycle and stop proliferation, resulting in a decreased incidence of cancer. Caffeine amounts at $1 \mathrm{mM}$ on epithelial cells have shown decreased the $\mathrm{G} 2$ arrest. ${ }^{53,54}$ Coca extract was shown to have an increasing trend in the appearance of the hypodiploid sub- $\mathrm{G}_{1} / \mathrm{G}_{0}$ phase, with increasing Cocoa procyanidin-rich extract concentration, indicative of DNA damage, and cell death. ${ }^{55}$ The ERK $1 / 2$ pathway impairs MAP kinase; therefore, we see a decrease in S phase.$^{56}$ Due to the decrease in DNA synthesis this may be a trend between proliferation and cell cycle data. High Cola concentrations show an increased presence of cells in the $\mathrm{G}_{1}$ phase and a lower proliferation showing that cells are surviving but proliferating which generate a low proliferation rate.

\section{Integrin expression}

Figure 5 showed initial adhesion of HFF-1 cells to fibronectin coated surfaces increased in the presence of higher concentrations of Cola, suggesting an increase in $\alpha 5 \beta 1$ integrin expression, a receptor specific to fibronectin binding. These interactions show that cell adhesion, through integrin expression results in morphology change in cell shape, growth rate, and differentiation allowing the ability to thrive in different environments. ${ }^{57-59}$ Fibronectin interact with cells mostly via integrins $\alpha v \beta 3$ and $\alpha 5 \beta 1$ during tissue repair process., 300 However there were no observed changes in the expression of $\alpha 5 \beta 1$ integrin in Cola concentrations $1.5 \%, 6.0 \%$, and $10.0 \%$.

It has been shown in recent articles that increase in $\beta 1$ integrin expression can be due to high glucose amounts which coordinate an increase in levels of mRNA encoding fibronectin and its corresponding receptor. ${ }^{61}$ Therefore, determination of integrin specificity with specific ECM domains is important in maintaining cell homeostasis, host defense and tissue maintenance. ${ }^{62}$

Further, binding of integrins to the ECM facilitates cell attachment via a signaling cascade that lead to fibrillogenesis ${ }^{63}$ Fibroblasts cultured in fibronectin require ubiquitination of integrin controls migration through lysosomal degradation via the endosomal sorting complex required for transport. ${ }^{64}$

$\alpha 5 \beta 1$ Integrin binding serve as a mode for both internal and external cell signaling, and promotes cell migration, cell survival and cell proliferation. ${ }^{65}$ Integrin $\beta 1$ subunit mediates the attachment of fibroblasts to collagen type I and fibronectin, suggesting that integrin $\beta 1$ would be a key factor in the focal adhesion, cell migration and cell proliferation when in the abundance of fibronectin. ${ }^{21,66}$ Due to the increase in expression of these surface proteins, there is an increased 
connection to fibronectin-rich environments, and will therefore have an increased rate of initial adhesion in the presence of increased Cola concentrations.

An increase in focal adhesion of HFF-1 cells to fibronectin in the presence of increased concentrations of Cola suggests that there could be an increase in the expression and interaction of $\alpha 5 \beta 1$ integrins on the cell surface of HFF-1 cells to fibronectin rich ECM environments. However further test should be completed.

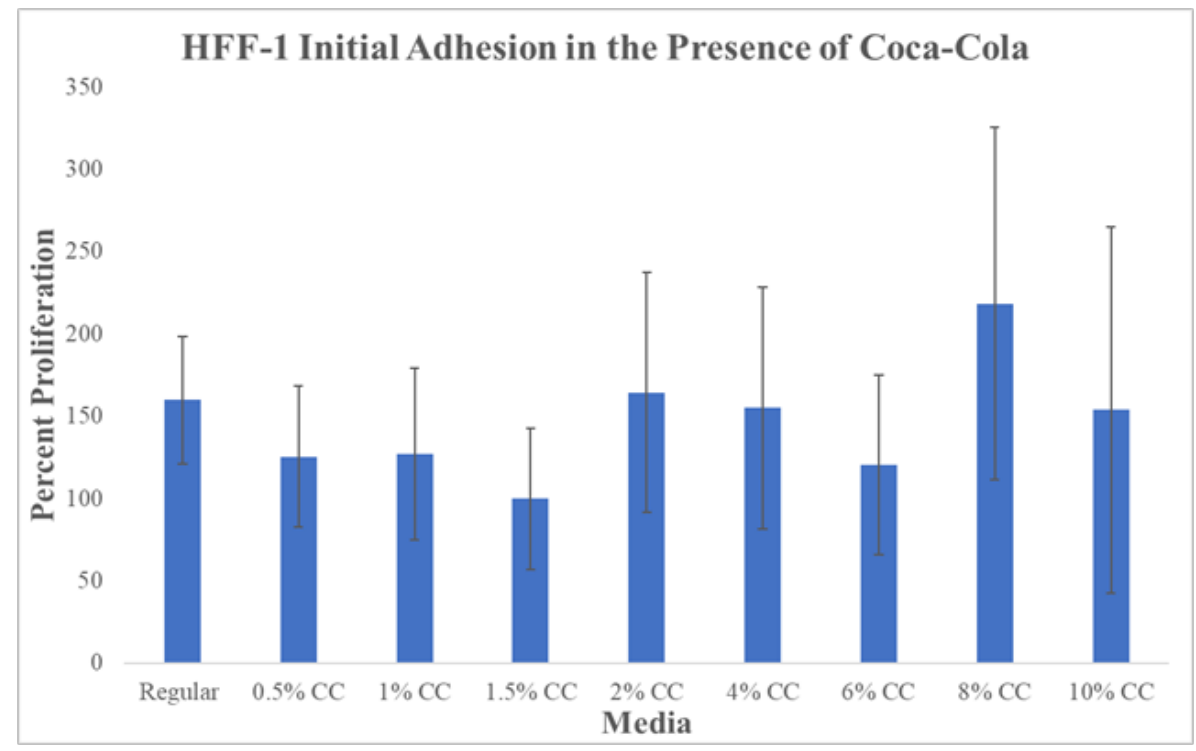

Figure 5 Initial Adhesion.

There is no statistically significant difference between HFF-I initial adhesion in Cola or regular media. Graph of HFF-I initial adhesion on I0 $\mu$ / $\mathrm{mL}$ fibronectin initially coated wells. Black brackets indicate standard deviation. $\mathrm{N}=9$. All $\mathrm{P}$ values marked with '*' were $\mathrm{P}<0.05$, considered statistically significant when compared to Regular Media. Cola was stored at an average temperature based on human consumption (refrigerator) and then heated in a bath at $37^{\circ} \mathrm{C}$ before plating. Comparison is from each result from regular. The data compares all media types to the lowest initial adhesion percentage which was observed at I.5\% Cola concentration at Day 0 (I hour incubation). I.5\% Cola initial adhesion was set to $100 \%$ percent for comparison between media conditions. The two lowest initial adhesion percentages were observed at $1.5 \%$ and $6 \%$ Cola conditions. The highest initial adhesion observed was at $8 \%$ Cola concentration. Cells were seeded at 10,000 cells per well in $0.5 \mathrm{~mL}$ of regular media or Cola concentration media. There is a trend that high concentrations of Cola generate higher levels of initial adhesion than low concentrations of Cola.

\section{Conclusion and future studies}

An increase in these interactions suggest that the tension between integrins to a fibronectin surface are highly increased, therefore not allowing cells to be able to detach from the surface to circularize to proliferate..$^{57}$ Therefore, Cola beverage has an increase in initial adhesion of fibroblasts, yielding to a decreased rate of HFF-1 proliferation. Cell Cycle analysis confirms this revealing an increase in the $G_{1}$ phase and decrease in the $S$ phase. Visual confirmation and cell morphology also verifies the effect with increase in Cola concentration.

Fibroblast can secrete their own extracellular matrix proteins to restructure their surrounding environment. ${ }^{49}$ Collagen and fibronectin are excreted by HFF-1 cells dependent on their surrounding environment. As seen in Figure 1, HFF-1 cells grown in the presence of a fibronectin-rich environment excrete high amounts of collagen This is observed because these cells were introduced into an environment where they were in need of collagen, and because there was none provided for them, they secreted their own to survive. Fibroblasts are key initiators in the wound healing process, and the fact that they can excrete their own extracellular matrix proteins, is the key factor why they play such an important role. In future studies, the secretion of fibronectin and collagen should be examined in the presence of different concentrations of Cola, to better understand this beverage's impact on fibroblasts' role in the wound healing process.

\section{Acknowledgments}

We would like to thank our lab partners: Brianna Bucci, Atherton Kniseley, Nikita Vaghasia, and Kyle Eckhart, we could not have done any of this without them; and Dr. Bill Tawil and Melissa McCoy for supporting our group through our experiments and encouraging our research.

\section{Author contributions}

The article was written through contributions of all authors. All authors have given approval to the final version of the manuscript.

\section{Funding sources}

California State University, Channel Islands, Camarillo, CA. Extended Education-CSUCI

\section{Conflict of interest}

Author declares that there is no conflict of interest.

\section{References}

1. Nielsen SJ, Popkin BM. Changes in beverage intake between 1977 and 2001. Am J Prev Med. 2004;27(3):205-210. 
2. Alkhedaide A, Soliman MM, Salah-Eldin AE, et al. Chronic effects of soft drink consumption on the health state of Wistar rats: A biochemical, genetic and histopathological study. Mol Med Rep. 2016;13(6):5109-5117.

3. Foolen J, Shiu JY, Mitsi M, et al. Full-Length Fibronectin Drives Fibroblasts Accumulation Surface of Collagen Microtissues during Cell-Induced Tissue Morphogenesis. PLoS One. 2016;11(8):e160369.

4. Myles IA. Fast Food Fever: Reviewing the Impacts of the Western Diet on Immunity. Nutr J. 2014;13:61.

5. Vartanian LR, Schwartz MB, Brownell KD. Effects of Soft Drink Consumption on Nutrition and Health: A Systematic Review and MetaAnalysis. Am J Public Health. 2007;97(4):667-675.

6. Nowacki M, Adamowicz J, Olkowska J, et al. Non-alcoholic beverages, unknown influence on cell proliferation-in vitro study. Ann Agric Environ Med. 2014;21(1):113.

7. Brown CM, Dulloo AG, Montani JP. Sugary drinks in the pathogenesis of obesity and cardiovascular diseases. Int J Obes (Lond). 2008;32(Suppl 6):S28-S34

8. Adamowicz J, Drewa T. Is there a link between soft drinks and erectile dysfunction? Cent European J Urol. 2011;64(3):140-143.

9. Xuan YH, Huang BB, Tian HS, et al. High-Glucose Inhibits Human Fibroblast Cell Migration in Wound Healing via Repression of bFGFRegulating JNK Phosphorylation. PLoS One. 2014;9(9):e108182.

10. Gosain A, DiPietro LA. Aging and wound healing. World J Surg. 2004;28(3):321-326.

11. Broughton G, Janis JE, Attinger CE. The basic science of wound healing. Plast Reconstr Surg. 2006;117(7 Suppl):12S-34S.

12. Campos AC, Groth AK, Branco AB. Assessment and nutritional aspects of wound healing. Curr Opin Clin Nutr Metab Care. 2008;11(3):281-288.

13. Darby IA, Laverdet B, Bonté F, et al. Fibroblasts and myofibroblasts in wound healing. Clin Cosmet Investig Dermatol. 2014;7:301-311.

14. Da Rocha-Azevedo B, Ho CH, Grinnell F. Fibroblast Cluster Formation on 3D Collagen Matrices Requires Cell Contraction-Dependent Fibronectin Matrix Organization. Exp Cell Res. 2013;319(4):546-555.

15. Singh P, Carraher C, Schwarzbauer JE. Assembly of Fibronectin Extracellular Matrix. Annu Rev Cell Dev Biol. 2010;26:397-419.

16. Chen ZJ, Yang JP, Wu BM, et al. A Novel Three-Dimensional Wound Healing Model. J Dev Biol. 2014;2(4):198-209.

17. Khan TA, Sievenpiper JL. Controversies about sugars: results from systematic reviews and meta-analyses on obesity, cardiometabolic disease and diabetes. Eur J Nutr. 2016;55(Suppl 2):25-43.

18. Bianconi D, Unseld M, Prager GW. Integrins in the Spotlight of Cancer Int J Mol Sci. 2016;17(12):E2037.

19. https://www.atc c.org/Products / A $11 /$ S C R C - 1041 aspx\#documentation.\%2016\%20March\%202017

20. Tazehkand MN, Moridikia A, Hajipour O, et al. The effects of 4-MEI on cell proliferation, DNA breaking and DNA fragmentation. Bratisl Lek Listy. 2016;117(7):371-375.

21. Shangxi Liu, Xu Shi-wen, Katrin Blumbach, et al. Expression of integrin $\beta 1$ by fibroblasts is required for tissue repair in vivo. $J \mathrm{Cell} \mathrm{Sci}$. 2010;123(21):3674-3682.

22. Bellis SL. Advantages of RGD Peptides for Directing Cell Association with Biomaterials. Biomaterials. 2011;32(18):4205-4210.

23. Sawicka KM, Seeliger M, Musaev T, et al. Fibronectin Interaction and Enhancement of Growth Factors: Importance for Wound Healing. Adv Wound Care (New Rochelle). 2015 Aug 1;4(8):469-478.
24. Wagner W, Wehrmann M. Differential cytokine activity and morphology during wound healing in the neonatal and adult rat skin. $J$ Cell Mol Med. 2007;11(6):1342-1351.

25. Kanazawa S, Fujiwara T, Matsuzaki S, et al. bFGF regulates PI3kinase-Rac1-JNK pathway and promotes fibroblast migration in wound healing. PLoS One. 2010;5(8):e12228.

26. Landman KA, Cai AQ, Hughes BD. Travelling waves of attached and detached cells in a wound-healing migration assay. Bull Math Biol. 2007;69(7):2119-38.

27. Clark RA, McCoy GA, Folkvord JM, et al. TGF- $\beta 1$ stimulates cultured human fibroblasts to proliferate and produce tissue-like fibroplasia: a fibronectin matrix-dependent event. J Cell Physiol. 1997;170(1):69-80.

28. Hocking DC, Chang CH. Fibronectin matrix polymerization regulates small airway epithelial cell migration. Am J Physiol Lung Cell Mol Physiol. 2003;285(1):L169-L179.

29. Hocking DC, Sottile J, Langenbach KJ. Stimulation of integrinmediated cell contractility by fibronectin polymerization. $J$ Biol Chem. 2000;275(14):10673-10682.

30. Mercurius KO, Morla AO. Inhibition of vascular smooth muscle cell growth by inhibition of fibronectin matrix assembly. Circ Res. 1998;82(5):548-556.

31. Pineda-Lucena A, Núñez De Castro I, Lozano RM, et al. Effect of low ph and heparin on the structure of acidic fibroblast growth factor. Eur $J$ Biochem. 1994;222(2):425-431.

32. Elliott SS, Keim NL, Stern JS, et al. Fructose, weight gain, and the insulin resistance syndrome. Am J Clin Nutr. 2002;76(5):911-22.

33. Donejko M, Przylipiak A, Rysiak E, et al. Influence of Caffeine and Hyaluronic Acid on Collagen Biosynthesis in Human Skin Fibroblasts. Drug Des Devel Ther. 2014;8:1923-1928.

34. Lauffenburger DA, Horwitz AF. Cell migration: a physically integrated molecular process. Cell. 1996;84(3):359-369.

35. Webb DJ, Parsons JT, Horwitz AF. Adhesion assembly, disassembly and turnover in migrating cells - over and over and over again. Nat Cell Biol. 2002;4(4):E97-E100.

36. Ridley AJ, Schwartz MA, Burridge K, et al. Cell migration: integrating signals from front to back. Science. 2003;302(5651):1704-1709.

37. SchwartzMA.Integrins andExtracellularMatrix in Mechanotransduction. Cold Spring Harb Perspect Biol. 2010;2(12):a005066.

38. Sevilla CA, Dalecki D, Hocking DC. Hocking. Extracellular Matrix Fibronectin Stimulates the Self-Assembly of Microtissues on Native Collagen Gels. Tissue Eng Part A. 2010;16(12):3805-3819.

39. Gui L, Wojciechowski K, Gildner CD, et al. Identification of the heparin-binding determinants within fibronectin repeat III1: role in cell spreading and growth. J Biol Chem. 2006;281(46):34816-34825.

40. Sottile J, Shi F, Rublyevska I, et al. Fibronectin-dependent collagen I deposition modulates the cell response to fibronectin. Am J Physiol Cell Physiol. 2007;293(6):C1934-C1946.

41. Chiu VC, Haynes DH. High and low affinity $\mathrm{Ca}^{2+}$ binding to the sarcoplasmic reticulum: use of a high-affinity fluorescent calcium indicator. Biophys J. 1977;18(1):3-22.

42. Mosmann T. Rapid colorimetric assay for cellular growth and survival: application to proliferation and cytotoxicity assays. J Immunol Methods. 1983;65(1-2):55-63

43. Vistica DT, Skehan P, Scudiero D, et al. Tetrazolium-based assays for cellular viability: a critical examination of selected parameters affecting formazan production. Cancer Res. 1991;51(10):2515-2520. 
44. Mould AP, Akiyama SK, Humphries MJ. Regulation of Integrin $\alpha 5 \beta 1-$ Fibronectin Interactions by Divalent Cations: evidence for distinct classes of binding sites for $\mathrm{Mn}^{2+}, \mathrm{Mg}^{2+}$, AND Ca ${ }^{2+}$ J Biol Chem. 1995;270(44):26270-26277.

45. Leung CW, Laraia BA, Needham BL, et al. Soda and Cell Aging: Associations Between Sugar-Sweetened Beverage Consumption and Leukocyte Telomere Length in Healthy Adults From the National Health and Nutrition Examination Surveys. Am J Public Health. 2014;104(12):2425-2431.

46. Tatler AL, Barnes J, Habgood A, et al. Caffeine inhibits TGF $\beta$ activation in epithelial cells, interrupts fibroblast response to TGF $\beta$, and reduces established fibrosis in ex vivo precision-cut lung slices. Thorax. 2016;71(6):565-567.

47. Morita T, Uneyama C. Genotoxicity assessment of 4-methylimidazole: regulatory perspectives. Genes Environ. 2016;38:20.

48. Alleva R, Borghi B, Santarelli L, et al. In vitro effect of aspartame in angiogenesis induction. Toxicol In Vitro. 2011;25(1):286-293.

49. Rabinovitch P. Introduction to Cell Cycle Analysis. USA: Phoenix Flow Systems, Inc; 2010.

50. Iwakura T, Fujigaki Y, Fujikura T, et al. A High Ratio of G1 to G0 Phase Cells and an Accumulation of G1 Phase Cells before S Phase Progression after Injurious Stimuli in the Proximal Tubule. Physiol Rep. 2014;2(10):e12173.

51. Bertoli C, Skotheim JM, de Bruin RA. Control of cell cycle transcription during G1 and S phases. Nat Rev Mol Cell Biol. 2013;14(8):518-528.

52. Kono T, Tanii T, Furukawa M, et al. Cell cycle analysis of human dermal fibroblasts cultured on or in hydrated type I collagen lattices. Arch Dermatol Res. 1990;282(4):258-262.

53. Tiwari KK, Chu C, Couroucli X, et al. Differential concentrationspecific effects of caffeine on cell viability, oxidative stress, and cell cycle in pulmonary oxygen toxicity in vitro. Biochem Biophys Res Commun. 2014;450(4):1345-1350.

54. Cortez D. Caffeine Inhibits Checkpoint Respones without Inhibiting the Ataxia-Telangiectasia-mutated(ATM) and ATM- and Rad3-related (ATR) Protein Kinases. 2003. J Biol Chem. 2003;278(39):37139-37145.
55. Taparia S, Khanna A. Effect of Procyanidin-rich Extract from Natural Cocoa Powder on Cellular Viability, Cell Cycle Progression, and Chemoresistance in Human Epithelial Ovarian Carcinoma Cell Lines. Pharmacogn Mag. 2016;12(Suppl 2):S109-S115.

56. Buonomo R, Giacco F, Vasaturo A, et al. PED/PEA-15 Controls Fibroblast Motility and Wound Closure by ERK1/2-Dependent Mechanisms. J Cell Physiol. 2012;227(5):2106-2116.

57. Dalton SL, Scharf E, Briesewitz R, et al. Cell Adhesion to Extracellular Matrix Regulates the Life Cycle of Integrins. Mol Biol Cell. 1995;6(12):1781-1791.

58. Roth T, Podestá F, Stepp MA, et al. Integrin overexpression induced by high glucose and by human diabetes: potential pathway to cell dysfunction in diabetic microangiopathy. Proc Natl Acad Sci U S A. 1993;90(20):9640-9644.

59. Koivisto L, Heino J, Häkkinen L, et al. Integrins in Wound Healing. Adv Wound Care (New Rochelle). 2014;3(12):762-783.

60. Rahmouni S, Lindner A, Rechenmacher F, et al. Hydrogel micropillars with integrin selective peptidomimetic functionalized nanopatterned tops a new tool for the measurement of cell traction forces transmitted through $\alpha v \beta 3$ - or $\alpha 5 \beta 1$-integrins. Adv Mater. 2013;25(41):5869-5874.

61. Retta SF, Cassarà G, D'Amato $M$, et al. Cross Talk between $\beta$ and $\alpha_{\mathrm{v}}$ Integrins: $\beta_{1}$ Affects $\beta_{3}$ mRNA Stability. Mol Biol Cell. 2001;12(10):3126-3138.

62. Bonnans C, Chou J, Werb Z. Remodelling the extracellular matrix in development and disease. Nat Rev Mol Cell Biol. 2014;15(12):786-801.

63. Moreno-Layseca P, Streuli CH. Signalling pathways linking integrins with cell cycle progression. Matrix Biol. 2014;34:144-53.

64. Lobert $\mathrm{VH}$, Brech A, Pedersen NM, et al. Ubiquitination of $\alpha 5 \beta 1$ intergrin controls fibroblast migration through lysosomal degradation of fibronectin-integrin complexes. Dev Cell. 2010;19(1):148-59.

65. Ata R, Antonescu CN. Integrins and Cell Metabolism: An Intimate Relationship Impacting Cancer. Int J Mol Sci. 2017;18(1):E189.

66. Loh JT, Su IH. Post-translational modification-regulated leukocyte adhesion and migration. Oncotarget. 2016;7(24):37347-37360. 